\title{
Género y Derecho a la Comunicación: la (in)visibilidad de los discursos feministas en la esfera pública contemporánea
}

Gender and Right to Communicate: the (in)visibility offeminist discourses in the contemporary public sphere

Gênero e Direito à Comunicação: a (in)visibilidade dos discursos feministas na esfera pública contemporânea

\author{
Janara SOUSA \\ Universidade de Brasília (Brasil) \\ janara.sousa@gmail.com \\ Gerson SCHEIDWEILER \\ Faculdade de Comunicação (FAC/UnB) (Brasil) \\ geh.scheid@gmail.com
}

Chasqui. Revista Latinoamericana de Comunicación

N. ${ }^{\circ}$ 148, diciembre 2021 - marzo 2022 (Sección Monográfico, pp. 107-124)

ISSN 1390-1079 / e-ISSN 1390-924X

Ecuador: CIESPAL

Recibido:31-o3-2021 / Aprobado: 12-11-2021 


\title{
Resumen
}

Este artículo discute cómo la producción delos discursos feministas hacialímites periféricos en la esfera pública constituye un instrumento de dominación que daña el potencial de influencia de los movimientos de mujeres ante la opinión pública. Para ello movilizamos, con base en la bibliografía consultada, las críticas a la generalización de la "esfera pública" habermasiana, demostrando la existencia de diferentes "públicos" y sus distintas condiciones de influencia discursiva. A continuación, a través de la investigación documental, analizamos los planes de acción de las cuatro Conferencias Mundiales de Mujeres ocurridas en el marco de las Naciones Unidas, demostrando cómo las mujeres pasaron a ver en el derecho a la comunicación un mecanismo de resistencia necesario para su fortalecimiento simbólico.

Palabras clave: Género; Derecho a la Comunicación; Esfera Pública; Feminismo.

\begin{abstract}
This article discusses how moving away from feminist discourse to peripheral limits in the public sphere is an instrument of domination that undermines the potential influence of women's movements on public opinion. To this end, we mobilize criticisms of the generalization of the habermasian "public sphere", demonstrating the existence of different "publics" and their different conditions of discursive influence. Then, through content analysis, we analyze the chapters dedicated to the Communication action plans of the four World Conference of Women within the United Nations. Finally, we demonstrate how women came to view the right to communicate as a necessary resistance mechanism and solution for their symbolic domination.
\end{abstract}

Keywords: Gender; Right to Communicate; Public Sphere; Feminism.

\section{Resumo}

Este artigo discute como a produção de discursos feministas em limites periféricos na esfera pública constitui um instrumento de dominação que prejudica o potencial de influência dos movimentos de mulheres junto à opinião pública. Para isso mobilizamos, com base na bibliografia consultada, as críticas feministas à generalização da "esfera pública" habermasiana, demonstrando a existência de diferentes "públicos" e suas distintas condições de influência discursiva. Em seguida, por meio de pesquisa documental, analisamos os capítulos dedicados à Comunicação nos planos de ação das quatro Conferências Mundiais de Mulheres ocorridas no âmbito das Nações Unidas, demonstrando como as mulheres passaram a ver no acesso aos meios de comunicação o mecanismo de resistência necessário para seu fortalecimento simbólico.

Palavras-chave: Gênero; Direito à Comunicação; Esfera Pública; Feminismo. 


\section{Introducción}

El periodo comprendido entre 1975 y 1985 fue considerado por las Naciones Unidas como la Década para las Mujeres. El recorte temporal, en medio a la Guerra Fría, estaba contaminado por las disputas estratégicas entre Occidente y Oriente, y por la lucha por mayor presencia de los países del Sur en las discusiones internacionales. El contexto llevó a las Naciones Unidas a desarrollar estudios para proponer más armonía en las relaciones entre los estados-miembro, incluso protagonizando discusiones que buscaron soluciones para combatir desigualdades de naturaleza política, social y económica. Entre ellas, ganaron destaque las acciones a favor del empoderamiento de las mujeres - que dio nombre a la década - y, en paralelo, estudios para rediscutir el flujo global de información, altamente concentrado en las potencias globales, en la figura de las grandes agencias internacionales de noticias.

Los dos temas, aunque no presenten una correlación previa, sino por la fecha en que ganaron visibilidad, tuvieron cierta convergencia durante el trabajo de la Comisión Internacional para el Estudio de los Problemas de la Comunicación, presidida por eljurista y periodista irlandés Sean MacBride. La Comisión, creada en 1977, tenía el objetivo de proponer soluciones para que se implementara una Nueva Orden Mundial de la Información y de la Comunicación (Nomic) - proyecto de interés de los países no alineados - y operó en el ámbito de la Organización de las Naciones Unidas para la Educación, la Ciencia y la Cultura (Unesco). Integraron su composición 16 miembros elegidos por su reconocida actuación internacional, pero, aunque la Década para las Mujeres estuviera en pleno vigor, ninguna mujer había sido asignada como integrante titular. La desistencia de Marshall Mcluhan, prestigioso investigador canadiense, por problemas de salud permitió la indicación de Betty Zimmerman, entonces directora de la Radio Canada International, convirtiéndose en la única representación femenina entre los miembros (Gallagher, 2011).

En 1979, gracias a una solicitud de Zimmerman, la Comisión incluyó entre los temas investigados el papel de las mujeres en las comunicaciones, arrojando luz sobre las desigualdades de género imbricadas en las relaciones de producción mediática, generando un estudio aparte. En 1980, durante la $21^{\mathrm{a}}$ Conferencia General de la Unesco, en Belgrado, el informe final de la Comisión fue aprobado por consenso, pasando a llamarse Many Voices, One World (Un Solo Mundo, Voces Múltiples), y trajo una serie de reflexiones acerca de los efectos del flujo desigual de informaciones causado por la concentración de los polos de emisión en países desarrollados y 82 recomendaciones que deberían implementarse para causar un equilibrio informacional, pasando por la urgente necesidad de democratización de los medios de comunicación y por la asunción de la comunicación como un derecho humano. Entre esas recomendaciones, apenas una se refería a la corrección de las desigualdades de género, justamente referentes a la singular petición de Zimmerman, que se convirtió en un capítulo 
del Informe intitulado Equal Rights for Women (Derechos Iguales para las Mujeres).

No hay discusión sobre la situación de las mujeres en relación a la transnacionalización, a la publicidad, a las infraestructuras, a los comunicadores profesionales, a la formación de la opinión pública - todas esas cuestiones habrían sido beneficiadas a partir de un análisis en términos de las relaciones y diferencias de género. En cambio, la "cuestión" de las mujeres es colocado en dos páginas sobre "derechos iguales para las mujeres", como se esos derechos no estuvieran relacionados a los otros asuntos abordados en el informe ${ }^{1}$ (Gallagher, 2011, p. 453)

El trabajo final de la Comisión sufrió diversas críticas, en primer lugar, por el carácter "utópico" y “abstracto" de las soluciones presentadas, y, en segundo lugar, por el boicot causado por el Reino Unido y por los Estados Unidos, que acusaron a la Unesco de actuar de manera activista y polarizada. Había natural interés de esos países en el control de las informaciones y en la protección de sus empresas de medios, que se beneficiaban económicamente del modelo hasta entonces en vigor. Todavía en 1980, las Naciones Unidas y la Unesco realizaron tres grandes estudios sobre las mujeres y los medios de comunicación, además de haber financiado por lo menos 12 encuentros nacionales e internacionales sobre el tema, creando una perspectiva de que los dos temas poseían una evidente interfaz.

Para el desarrollo de este artículo, cuestionamos de qué forma el derecho a la comunicación puede servir como una acción estratégica para posibilitar la presencia de los discursos producidos por el movimiento feminista en la esfera pública contemporánea y qué mecanismos deben superarse para que esos discursos sean capaces de influenciar la opinión pública. Nuestro objetivo es demostrar cómo el derecho a la comunicación no se pensó bajo la óptica de la mujer y, si no se lo problematiza bajo esa perspectiva, puede contribuir con los instrumentos de dominación que inciden sobre las mujeres. Nuestra investigación, de naturaleza teórico-conceptual, analiza los estudios feministas relacionados a la presencia de la mujer en la esfera pública y su bajo acceso a los medios de comunicación.

En conjunto con la movilización teórica, asumimos como axioma el entendimiento de que la garantía necesaria para que hombres y mujeres puedan hablar, escribir e imprimir libremente, bajo cualquier medio, como definen los documentos internacionales relacionados a los derechos humanos, se pone todavía más compleja con el advenimiento de las comunicaciones electrónicas, en especial el radio y la televisión. Esos siempre fueron controlados por conglomerados comunicacionales que, en su mayoría, operan a partir de una lógica económica y principalmente masculina.

1 Traducción nuestra. 


\section{La relectura de la esfera pública bajo una perspectiva feminista}

Uno de los caminos para comprender los motivos por los cuales las mujeres no han tenido acceso a los medios de comunicación (sea en posiciones decisorias sea en el pluralismo de voces) está vinculado a una dimensión político-estructural, cultural y económica. La dimensión político-estructural se constituye por la garantía tardía de derechos formales a las mujeres para participar de forma autónoma de las actividades que extrapolan el ámbito doméstico, desencadenando un desequilibrio en las relaciones de poder entre los individuos, aunque, en aspectos formales, detengan los mismos derechos. La dimensión cultural abarca la naturalización de las desigualdades entre hombres y mujeres por la justificación biológica que pasa a definir sus papeles sociales, especialmente por la responsabilización de la mujer por los cuidados de los hijos y el marido, lo que acaba por ocupar la mayor parte de su tiempo libre. Ese contexto se origina de una división sexual del trabajo, en que a las mujeres les cabe el papel reproductivo y, solamente en el tiempo libre, tienen la oportunidad de ocupar el mercado formal de trabajo. En la dimensión económica, a su vez, tenemos la baja remuneración que incide sobre la mayor parte de las mujeres en comparación a los hombres que ocupan las mismas funciones y, también, la dificultad de ascender en la estructura jerárquica de las empresas.

Las tres dimensiones presentan reflejos de desigualdades que pueden explicarse por las críticas feministas a la dualidad entre el público y el privado, que han demostrado los límites del liberalismo por su incapacidad de comprender las relaciones dispares de poder que ocurren aunque haya la igualdad formal de derechos.

Asumir que relaciones desiguales pueden causar perjuicio a la autonomía de las mujeres es el primer paso para que se comprenda que su actuación en la esfera pública estará, desde el origen, plagada de condiciones limitantes. Esa perspectiva fue discutida por Fraser (1993) cuando se propuso a hacer una relectura del concepto de esfera pública bajo una óptica feminista. Pero, antes de adentrarnos en sus contribuciones, vamos a reanudar el concepto habermasiano de esfera pública burguesa.

Habermas no fue capaz de reconocer, de inicio, que la esfera pública, aunque garantizara mayor poder a la sociedad, era un espacio en que las diferencias entre grupos de individuos generarían capacidades distintas de influenciar la toma de decisiones. Aunque se buscara generalizar que la esfera pública abarcaba todos los individuos y pasaba a constituir la noción de "público", en singular, derivando de una noción también generalista de "opinión pública". No es difícil comprender que el público del que estamos hablando sería mayoritariamente integrado por hombres blancos propietarios. Fraser (1993) demuestra que no es posible relacionar la noción de esfera pública a la formación de la noción de un "público" singular, sino a la percepción de que la esfera pública burguesa era integrada por diversos "contrapúblicos" concurrentes, diferenciados por las 
características y por la cualidad de interacción discursiva. Para ella, existe en la esfera pública una multiplicidad de públicos que pueden categorizarse en: a) públicos débiles; b) públicos fuertes; y c) contrapúblicos subalternos.

Los públicos débiles son aquellos en que la práctica discursivo-deliberativa consiste exclusivamente en la formación de opinión y no engloba la toma de decisiones, como el caso de las empresas de comunicación, que influencian directamente la constitución del "clima de opinión". Los públicos fuertes, por otro lado, son aquellos que poseen condiciones tanto de formar opinión como de tomar decisiones, como es el caso del parlamento, que posee un espacio interno de discusión, visibilidad pública y detiene poder en la creación de normas, leyes y políticas públicas. Ya los contrapúblicos subalternos son "espacios discursivos paralelos en donde los miembros de los grupos sociales subordinados inventan y hacen circular contra discursos, que, al mismo tiempo, les permiten formular interpretaciones de oposición acerca de sus identidades, intereses y necesidades" (Fraser, 1993, p. 54). Es el caso de lo que ocurre con los movimientos feministas, LGBTQIA+, negro y otros que integran clivajes sociales políticamente minoritarios ${ }^{2}$ en el acceso a los espacios formales de decisión política.

La existencia de contrapúblicos subalternos es necesaria en la medida en que son capaces de producir y diseminar identidades propias de esos grupos y constituir conceptos y definiciones de fenómenos que solo sus experiencias compartidas serían capaces de crearlos, posibilitando que los elementos que los hacen diferentes sean reconocidos y no sean factores limitantes de su performance pública. Fraser (1993) usa el caso del movimiento feminista estadunidense del final del siglo XX como un ejemplo típico de esa categoría. Para ella, la variedad de periódicos, librerías, programas académicos, convenciones y festivales les permitió a las feministas inventar nuevos términos para describir la realidad social, como sexismo, doble jornada de trabajo, violación marital, entre otros. Crear esos conceptos a partir de "interacciones discursivas" internas no solo fortaleció el movimiento, sino que creó condiciones para que esos conceptos desbordaran los límites del grupo y fueran incorporados a las agendas de discusión de otros públicos integrantes de la esfera pública (como la prensa), pudiendo así contribuir con la formación de opinión y el combate a las desigualdades y opresiones de género. Sin embargo, si las interacciones discursivas de los contrapúblicos subalternos son debilitadas o inhibidas por condiciones político-estructurales, culturales o económicas, entonces la posibilidad de autonomía se vuelve aún más escasa.

Los públicos fuertes y débiles, aunque detengan centralidad en la esfera pública por su mayor potencial de construir opinión generalizada y llevar a la

2 Trabajamos la idea de grupos minoritarios referenciando su presencia institucional en espacios de representación política. Aunque las mujeres integren la mayoría del electorado nacional brasileño y la mayoría de la población, su representación política todavía es pequeña. Lo mismo ocurre con los negros y los homosexuales. 
toma concreta de decisiones (sea directa o indirectamente), son presionados a convivir con demandas y conceptos que advienen de las actividades discursivas de los contrapúblicos subalternos. Cuanto más fortalecida la actividad de los contrapúblicos, cuanto más unísonos y visibles sus discursos, mayor es la potencialidad de reducir las distanciasjerárquicas quelos separan. La presiónque los contrapúblicos ejercen, creando hechos, literatura, símbolos, articulaciones en diferentes ámbitos, es una estrategia necesaria para influenciar la opinión pública, una vez que, sin eso, su invisibilidad sería inminente.

La crítica feminista a la esfera pública burguesa demuestra que hay un largo camino para alcanzarse una sociedad en que las desigualdades se corrijan. Para tener una esfera pública en que la actuación de un grupo no limite la actuación de otro, es necesario que haya espacio para que se incorporen agendas más allá de aquellas definidas por quien detiene mayor poder de influencia y decisión. Fraser (1993) considera que hay una ideología masculinista relacionada a los públicos fuertes y débiles porque estos son dominados por hombres u operan en una lógica construida por hombres. Es fácil percibir esta lógica cuando miramos la composición de los espacios formales de representación política, o las emisoras de radio y televisión, presididas principalmente por hombres alineados a los intereses del capital.

La contribución de la teoría feminista a la relectura de la esfera pública, a la luz de las reflexiones de Fraser (1993), muestra la necesidad de que existan políticas de redistribución en el acceso de los individuos a mecanismos capaces de contribuir con su potencial discursivo, recayendo sobre el Estado la tarea de proporcionar ese equilibrio, bajo el riesgo de no haber la garantía plena de libertad. Para eso, la autora traza una paradójica relación entre políticas de redistribución y políticas de reconocimiento. Para ella, mientras las políticas de redistribución deberían promover la mejor distribución de bienes materiales, de modo que no haya diferencias que limiten el acceso de determinados individuos a su plena condición de sujeto de derechos, al mismo tiempo son necesarias políticas que valoricen y reconozcan las diferencias entre los individuos para que no se homogenice y se oprima aquellos que no gozan del mismo estado de aquellos que integran grupos hegemónicos (Fraser, 2000). Si los contrapúblicos subalternos no poseen espacios de habla en los medios de comunicación por estar sometidos a opresiones interseccionales (de género, raza, generación y de clase social), entonces la jerarquía entre los públicos oprime sus derechos, especialmente el derecho a la comunicación, como veremos adelante. Los medios de comunicación de masas, que aún hoy operan en una lógica capitalista y masculinista, son recurso fundamental para el empoderamiento de las mujeres, como ya identificaron los movimientos feministas de la segunda mitad del siglo XX y comienzo del siglo XXI. La agenda de aquellos movimientos era de que los medios no deberían solo interrumpir la reproducción de estereotipos, sino incorporar a las mujeres en espacios de decisión en la definición de la programación. Esa reflexión puede notarse 
efectivamente en la sección J del Plan de Acciones de la Conferencia Mundial de Mujeres, que ocurrió en Beijing en 1995. El documento es una evolución crítica y refleja una mayor madurez de los problemas involucrando las cuestiones de género y los medios de comunicación, pues define que el acceso de las mujeres a los medios de comunicación sería una estrategia de resistencia frente a la baja capacidad de influencia sobre los públicos fuerte y débiles, fruto del histórico ocultamiento de las mujeres dentro de los límites de la esfera privada.

\section{El acceso de las mujeres a los medios de comunicación y la reproducción de estereotipos}

No es necesario que se vaya a fondo en la investigación sobre el contexto en que los medios de comunicación se establecen para percibir que el acceso de las mujeres a los medios de producción simbólico-mediática todavía es pequeño. La constante reproducción de estereotipos de género en la programación televisiva, en los anuncios publicitarios y el interés generalizado en no diseminar contenidos que rompan con la lógica centrada en la visión de mundo masculina es una demostración evidente de que las mujeres no están participando de las decisiones y de la curaduría de la programación de radio y televisión. Si bien el número de mujeres periodistas, publicitarias y actrices haya aumentado considerablemente a lo largo de las últimas décadas, pocas de ellas alcanzan espacios de decisión dentro de las empresas que operan los medios de comunicación públicos o privados. Esa realidad contribuye para que el periodismo dé "visibilidad a los actores que forman parte del campo político en sentido estricto y que ya poseen recursos para hacerse ver y oír" (Miguel \& Biroli, 2010, p. 13).

El avance de las tecnologías de comunicación ha garantizado, en los últimos años, un acceso mayor de las mujeres a herramientas que posibiliten expresar sus visiones de mundo, como es el caso de Internet y de los sitios de redes sociales capaces de hacer horizontal el flujo informacional, promoviendo lo que llamamos de "liberación del polo de emisión". Sin embargo, mismo con Internet, las empresas de comunicación todavía detienen gran parte del control sobre la producción simbólica. Internet se puede ver, en ese contexto, como un instrumento para operacionalizar la resistencia del movimiento feminista y darle visibilidad a su agenda, pero su efectividad recae en limitaciones técnicas que impiden la llegada de contenidos a todos los usuarios, una vez que también los sitios de redes sociales operan en una lógica alineada a intereses económicos que tiene en sus algoritmos los filtros necesarios para impedir la masificación de las publicaciones. ${ }^{4}$ De acuerdo a la Investigación Brasileña de Media (Pesquisa

3 Traducción nuestra.

4 Los sitios de redes sociales han sido tomados como instrumentos de lucha política, pero las empresas que los operan, como Facebook, han constantemente limitado el alcance de las publicaciones en búsqueda de inversiones. La necesidad de inversiones financieras para diseminar mensajes a otros grupos acaba por 
Brasileira de Mídia) de 2016 (Secom, 2016), la televisión todavía es apuntada como el medio más utilizado para que los ciudadanos y ciudadanas se informen sobre lo que pasa en Brasil (89\%), apareciendo Internet en un distante segundo lugar (49\%).

Biroli (2011, p. 73) señala que los estereotipos diseminados por los medios de comunicación surgen "como una dimensión de la imposición, por los grupos y estratos de grupos dominantes, de su visión de mundo. Y la media aparece como un instrumento central de su propagación ${ }^{5}$ ". De esa forma, no hay un compromiso para la superación de prejuicios y desigualdades, una vez que el control de las informaciones y la producción de la verdad "están en el centro de la dinámica de dominación”. Esa es una de las perspectivas que parecen derivar del pensamiento de Gramsci acerca de la manutención de la hegemonía por medio de aparatos privados que operan para mantener el poder de la clase social dominante a través del control de la producción simbólica, cultural y de ideas. La contribución de Gramsci al pensamiento marxista está justo en la comprensión de que la superestructura posee enorme influencia sobre la estructura. De esa manera, para que se promuevan cambios en el contexto de dominación, sería necesario conquistar el control de los mecanismos que mantienen la dominación por medio de la hegemonía de las ideas (Carnoy, 1986; Coutinho, 1989). Gramsci no pensaba la hegemonía bajo la perspectiva de género, pero sus ponderaciones refuerzan la tesis de que los medios de comunicación, mientras activos productores de bienes culturales, son también responsables por la dominación y que, si no sufren un proceso de restructuración, no tendrán cualquier interés para la corrección de desigualdades que ellos mismos contribuyen para promover.

La difusión de estereotipos de género por los media, en medio a una pluralidad de informaciones, genera una naturalización de las desigualdades entre hombres y mujeres, como por ejemplo, el refuerzo a la idea de que la actuación de la mujer es inherente y propia de la esfera privada, limitando la percepción de que hay un amplio espacio de actuación fuera de los límites del hogar y de la familia. Si los medios de comunicación poseen centralidad en la construcción del ambiente social, así como en la percepción sobre características de la propia identidad de determinados grupos, entonces es más que necesario que las mujeres lleven para dentro de estos medios sus propias experiencias convertidas en discurso, pues así dejarían su subalternidad de lado para realmente influenciar la percepción que se tiene sobre ellas junto a la opinión pública.

El acceso de las mujeres a los medios de comunicación está limitado, por una parte, por las dificultades causadas por su alejamiento histórico de la esfera pública; por la dificultad en ascender en lajerarquía organizativa y de decisión en

limitar la eficacia de esas herramientas como instrumento de resistencia y lucha, aunque sean recursos fundamentales para movilización en red, como bien demostró Castells (2012).

5 Traducción nuestra. 
las empresas de comunicación (incluso dentro de los sistemas públicos); y por el control de los mecanismos de producción de bienes simbólicos y culturales, que actúan en desfavor de los intentos de empoderamiento femenino, reforzando estereotipos y naturalizando las desigualdades.

Si bien a partir de la década de 1970 haya habido un incremento mayor de mujeres en el campo del periodismo, hay evidencias de que hay "dificultades de manutención y ascensión profesional, remuneración no acorde con la función desempeñada, [...] condiciones desiguales en el acceso a los espacios de poder y decisión [...]" (Rosa, 2014, p. 4). Una encuesta realizada con todas las empresas públicas de radiodifusión y los principales medios de comunicación privados de la Unión Europea indicó que de 3.376 puestos de responsabilidad en la toma de decisiones y en los Consejos de Administración de estas empresas, solo 1.037 (30\%) estaban ocupados por mujeres. Los datos muestran también que un tercio de los puestos de toma de decisiones en los servicios públicos de comunicación están ocupados por mujeres y una cuarta parte en empresas privadas (Ross, 2017).

El acceso desigual de las mujeres a los espacios de decisión en los medios de comunicación no se da sólo en referencia a los hombres, sino hasta entre las mujeres mismas. Mujeres negras poseen menor acceso que mujeres blancas; mujeres pobres, menos acceso que las mujeres ricas. Estas perspectivas interseccionales demuestran que, mismo si hubiera el mismo número de hombres y mujeres actuando en la producción de telenovelas, en las redacciones periodísticas, en las áreas de creación publicitaria, las experiencias retratadas serían de aquellas que ya vivencian previamente más privilegios.

\section{El derecho (humano) a la comunicación}

El derecho a la comunicación se considera un derecho de cuarta generación, integrado al rol de los derechos humanos (Ramos, 2005). En la evolución histórica, desde la segunda generación de los derechos humanos, el acceso a la información ya había sido concebido como un derecho necesario a la ciudadanía, especialmente en democracias representativas, así como la libertad de manifestación y expresión del pensamiento. El Estado no podría limitar el acceso de las personas a poder expresar sus ideas o buscar información, pues son dos condiciones necesarias para garantizar la libertad del ser humano. Los derechos ligados a la capacidad de emitir opiniones o recibir informaciones eran, sin embargo, restrictivos, puesto que no abarcaban la complejidad que gira alrededor de las necesidades de los individuos de exponer sus opiniones en los medios que se perciban necesarios (Ramos, 2005). Es a partir de ese axioma que el derecho a la comunicación está mencionado en el Informe Macbride como un

6 Traducción nuestra. 
derecho a garantizarse, esto es, fue positivado por el Estado para que los seres humanos alcancen la ciudadanía plena.

El derecho a la comunicación supone que el derecho de comunicar sea un proceso bidireccional, de dos flujos, "cuyos participantes - individuos o colectivos - mantienen un diálogo democrático y equilibrado 7" (Unesco, 1983). Aunque se suponga que los derechos humanos sean de aplicación universal, sin distinción de género, raza, clase social o generación, sus beneficios no se sienten de forma igual entre todos ellos, tampoco se concibieron de esa manera por la teoría liberal clásica. La universalidad intrínseca al concepto de "humano" oculta una serie de desigualdades que han oprimido históricamente diferentes grupos de "humanos", entre ellos las mujeres. Eso porque los diferentes papeles sociales atribuidos a hombres y mujeres, especialmente por la división sexual del trabajo, hace que los hombres tengan mayor presencia y visibilidad en la esfera pública. Susan Okin (1979) es una pensadora feminista que hizo una crítica a la universalidad propuesta por el pensamiento liberal. En su crítica a Rousseau, entiende que las concepciones originales del liberalismo suponían un humano atomizado. Para ella, si bien las mujeres fueran tan independientes en el estado de naturaleza como los hombres, su subordinación se dio desde el momento en que se formó la sociedad civil. Por ese motivo, cuando hablamos en derecho humano a la comunicación, faltó a los teóricos liberales y de la comunicación una reflexión acerca de las dificultades que algunos grupos tendrían para alcanzar la plenitud de ese derecho, por estar condicionados a filtros limitantes de su performance pública. Para la investigadora feminista Heike Jensen:

El marco general de interpretación de esos documentos de derechos humanos ha sido de naturaleza liberal tradicional, en que las violaciones de los derechos humanos se entienden tácitamente como acciones de agentes del Estado contra hombres políticamente activos en la esfera pública. Las violaciones de los derechos humanos de las mujeres han, en este contexto, en gran parte permanecido escondidas, y muchas veces aparecen como cuestiones privadas o como tradiciones culturales o religiosas ${ }^{8}$ (Jensen, 2006, p. 236).

Hay, por lo tanto, que problematizar la cuestión “¿de qué humanos hablamos cuando definimos un derecho humano?”. El materialismo histórico ya demostró, en el embate con la teoría liberal, que la garantía formal de derechos no es condición para que todos se beneficien sustantivamente de ellos. En ese sentido, los Estados que incorporan el derecho humano a la comunicación a sus marcos normativos, necesitan garantizar no solo el acceso a la información o la garantía de que los individuos puedan expresarse, sino garantizar los espacios para que las expresiones de sus pensamientos sean accedidas por los otros públicos que integran la esfera pública. Hay ahí un problema de naturaleza técnica,

7 Traducción nuestra.

8 Traducción nuestra. 
que reside en la cuestión acerca de cómo garantizar a los individuos acceso a los medios masivos de producción simbólica, operados por las empresas de comunicación públicas o privadas. Ya hubo en Brasil, y hay en algunos países, como Reino Unido y Canadá, experiencias positivas de implementación de sistemas públicos de comunicación, en que sus consejos curatoriales son integrados por miembros representativos de la sociedad civil. Se opera ahí un punto importante para el debate: el derecho a la comunicación no actúa en el ámbito individual, sino en el ámbito de las identidades colectivas. Al asumir esa premisa podemos engendrar mecanismos de participación popular en los medios de comunicación. Al delegar el ejercicio de ese derecho a representantes elegidos por los individuos, podemos operacionalizar la democratización de la comunicación y, de esa forma, reducir algunas desigualdades que operan en el centro de la producción simbólico-mediática.

Para eso es necesario que el derecho a la comunicación se incorpore como derecho constitucional, insertado en el ordenamiento jurídico de las naciones. En la Constitución brasileña de 1988, hay la garantía de libertad de manifestación del pensamiento, pero la posibilidad de que eso ocurra a través de cualquier medio no está explicada en el rol de derechos fundamentales, sólo en el capítulo especial dedicado al tema de la Comunicación Social, donde se define que el Estado no hará restricción a la manifestación de la expresión por cualquier forma, proceso o vehículo. Si por un lado no hay restricción del Estado, por otro no hay garantía de que cualquier vehículo deba difundir los pensamientos de los ciudadanos. Ahí está, por lo tanto, el motivo por el cual brasileños y brasileñas no gozan del pleno derecho a la comunicación: porque no se trata de una libertad negativa, en la que el Estado no debe interferir, sino de una libertad positiva, de modo que ese derecho solamente será garantizado cuando el Estado proporcione los mecanismos necesarios para tal. Por eso, la democratización de los medios de comunicación viene a debate - no refiriéndose apenas a la desconcentración de los medios, sino al acceso generalizado de los individuos alejados de la posibilidad de dar visibilidad a sus agendas, en una amplia política de redistribución, proporcionada por el Estado. Para Ramos (2005, p. 250), si no hay la circulación de informaciones en doble sentido, sin que haya diversas fuentes de información, sin el desarrollo de oportunidades para que los individuos tomen decisiones "basadas en el conocimiento completo de hechos heteróclitos y de puntos de vista divergentes" ${ }^{9}$, el derecho humano a la comunicación nunca será una realidad.

\section{Las Conferencias Mundiales de Mujeres y la Comunicación}

La movilización teórico-contextual que realizamos hasta ahora buscó demostrar que la esfera pública posee diferentes jerarquías de públicos, de los cuales los

9 Traducción nuestra. 
movimientos feministas integran lo que Fraser (1993) denominó "contrapúblicos subalternos". No obstante, esa subalternidad ha producido efectos políticos importantes para sus miembros, como la movilización de diversos actores sociales para debatir las dificultades que denuncian.

Para identificar cuáles reivindicaciones estuvieron relacionadas al campo de la Comunicación en el ámbito de los debates feministas internacionales, una vez que fueron los más amplios espacios de reflexión sobre las desigualdades de género en el mundo, realizamos una investigación documental en los Informes derivados de las cuatro Conferencias Mundiales de Mujeres ocurridas en el ámbito de las Naciones Unidas. El Cuadro 1 presenta las partes de los planes de acción de esos informes que se refieren al tema "comunicación" y cuál el enfoque dado por las conferencias a la relación entre los medios de comunicación y las agendas de los movimientos de mujeres.

Cuadro 1 - Conferencias Mundiales sobre la Mujer y la Comunicación

\begin{tabular}{|l|l|l|l|}
\hline Informe & Local y Año & $\begin{array}{l}\text { Párrafos/ } \\
\text { Artículos } \\
\text { destinados a la } \\
\text { "Comunicación" }\end{array}$ & Enfoque \\
\hline $\begin{array}{l}\text { I Conferencia } \\
\text { Mundial sobre la } \\
\text { Mujer }\end{array}$ & $\begin{array}{l}\text { Ciudad de } \\
\text { México, 1975 }\end{array}$ & 174 a 178 & $\begin{array}{l}\text { 1. Los medios de comunicación deben interrumpir la } \\
\text { reproducción de estereotipos de género. }\end{array}$ \\
\hline $\begin{array}{l}\text { II Conferencia } \\
\text { Mundial sobre la } \\
\text { Mujer }\end{array}$ & $\begin{array}{l}\text { Copenhague, } \\
1980\end{array}$ & 83 a 91 & $\begin{array}{l}\text { 1. Los medios de comunicación deben interrumpir la } \\
\text { reproducción de estereotipos de género. 2. Necesidades } \\
\text { de estudios sobre cómo se representa la mujer en los } \\
\text { medios de comunicación. }\end{array}$ \\
\hline $\begin{array}{l}\text { III Conferencia } \\
\text { Mundial sobre la } \\
\text { Mujer }\end{array}$ & Nairobi,1985 & 206 a 208 & $\begin{array}{l}\text { 1. Los medios de comunicación deben interrumpir la } \\
\text { reproducción de estereotipos de género. 2. Exigencia } \\
\text { de creación de redes de comunicación en las que haya } \\
\text { efectiva participación de las mujeres. }\end{array}$ \\
\hline $\begin{array}{l}\text { IV Conferencia } \\
\text { Mundial sobre la } \\
\text { Mujer }\end{array}$ & Beijing,1995 & 234 a 245 & $\begin{array}{l}\text { 1. La reproducción de estereotipos será interrumpida } \\
\text { con la inserción de las mujeres en los espacios de } \\
\text { decisión dentro de los medios de comunicación. }\end{array}$ \\
\hline
\end{tabular}

Fuente: Elaboración propia.

La I Conferencia Mundial sobre la Mujer ocurrió en 1975, en la Ciudad de México. El documento producido por las conferencistas resultó en una plataforma de acción que posee una sección especial denominada "Medios de Comunicación de Masas", con artículos que van desde el 174 al 181. De estos 7 artículos, 6 son dedicados a señalar que los medios de comunicación tienen potencial para causar cambios sociales y, por eso, deberían contribuir para combatir, y no ampliar, la diseminación de estereotipos de género. El primer artículo, por ejemplo, se dedica a exigir que más mujeres tengan participación en la toma de decisiones de los vehículos de comunicación, así como en puestos de trabajo como periodistas, editoras, entre otros. 
En la II Conferencia Mundial sobre la Mujer, ocurrida en 1980, en Copenhague, el informe final relacionó la comunicación a la temática de la educación, dispuesto en los artículos 83 a 91. La idea central presentada es de que los medios de comunicación de masas deben asumir su papel en la construcción de una sociedad más justa, debiendo superar la contradicción que existe ora en la difusión de una imagen estereotipada, ora en la diseminación de imágenes que muestren el real valor de la mujer. El texto también incentiva que se realicen estudios en el ámbito de los países para demostrar cómo la publicidad, la prensa y el entretenimiento representan a las mujeres por medio de los discursos que producen y vehiculan.

En el documento final de la III Conferencia Mundial sobre la Mujer, ocurrida en Nairobi, en 1985, el número de artículos dedicados a las acciones de comunicación se redujo a 3. Una vez más se evidenció que los medios de comunicación poseen un papel crítico en la reproducción de estereotipos de género. El informe retoma la necesidad de que más mujeres ocupen cargos de decisión junto a los vehículos de comunicación y, de forma inédita en los documentos, se exige que hayan redes de comunicación en que la participación de las mujeres sea efectiva: "Se debe auxiliar las organizaciones destinadas a promover el papel de las mujeres en el desarrollo como contribuyentes y beneficiarias en sus esfuerzos para establecer redes efectivas de comunicación e información" (Naciones Unidas, 1985, p. 50).

En la IV Conferencia Mundial sobre la Mujer, que ocurrió en Beijing en el año 1995, las mujeres dieron, entre todos los documentos, mayor énfasis a la comunicación. El documento aporta un análisis contextual de los problemas que involucran la comunicación y las mujeres, insertados en los artículos 234 a 245, con enfoque en la reproducción de los estereotipos y en la baja presencia de mujeres en espacios de decisión junto a los sistemas de comunicación. Es, en nuestro análisis, la primera vez que las mujeres mencionan su deseo de asegurar a todas (profesionales de comunicación o no) el acceso a información y a comunicación:

En virtud de los avances en la tecnología de las computadoras y televisión por satélite y cable, el acceso mundial a la información sigue aumentando y expandiéndose, con lo que se crean nuevas oportunidades para la participación de la mujer en las comunicaciones y en los medios de difusión, así como para la divulgación de información sobre la mujer. [...] Mientras la mujer no participe equitativamente en las esferas técnica y de adopción de decisiones dentro del contexto de las comunicaciones y los medios de difusión, incluidas las artes, seguirá siendo objeto de representaciones falsas y se seguirá desconociendo cómo es en realidad su vida (Naciones Unidas, 1996, p. 14).

Los documentos demuestran que, en el transcurso histórico, hubo un despertar cada vez mayor para la necesidad de que las mujeres tengan acceso a los medios de comunicación para que se corrijan desigualdades en la producción 
simbólica. Queda clara la comprensión de que el derecho a la comunicación necesita pensarse a partir de una perspectiva de género y que los medios de comunicación deben contribuir para su garantía. Se percibe, año a año, el avance en el debate para que haya una igualdad de género en la estructura productiva de los vehículos de comunicación. Se exige una amplia política de acceso a los espacios definidores de la programación de radio y televisión para que no se vehiculen imágenes deturpadas de las mujeres. Un ejemplo práctico de cómo eso ocurre es la común asignación de periodistas hombres para tratar de política o deportes, creando un locus simbólico de actuación (Miguel \& Biroli, 2010). La mayor presencia de mujeres tratando de esos temas llevaría a una producción de sentido que demostraría a la sociedad que estos temas representan espacios en donde la actuación de las mujeres es posible y valorada.

De esa manera, el avance de la IV Conferencia Mundial sobre la Mujer en relación a la Comunicación estuvo en observar que los medios de comunicación no deben verse como entidades alejadas de la actuación de las mujeres, sino que estas deberían incorporarse en estas entidades, para hacer que ellas diseminen susideasy formas dever el mundo. Se propone, sobre todo, quelas mujeres ocupen espacios de decisión para incorporar la perspectiva femenina en el proceso de producción simbólica, promoviendo una acción amplia de reconocimiento y garantizando el derecho a la comunicación en una dimensión colectiva y compartida. Pero se sabe que la perspectiva femenina no necesariamente representa una perspectiva feminista, ya que el feminismo tiene una base materialista histórica, con un fuerte enfoque en cuestionar la universalidad de los derechos humanos al exponer las tensiones entre patriarcado y capitalismo (Biroli, 2018). Así, no existe necesariamente una relación causal entre el número de mujeres que ocupan estos espacios y la mayor visibilidad de los discursos feministas, ya que las mujeres no aparecen como un grupo homogéneo y estos últimos exponen la lógica de subordinación que no siempre se incorpora a la productiva y dinámica de toma de decisiones de las organizaciones.

Por tanto, los capítulos dedicados a la Comunicación deben leerse combinados con aquellos que sugieren que las mujeres ocupen todos los espacios de toma de decisiones políticas (y no solo las empresas de comunicación), ya que existen otros espacios importantes en la definición de políticas públicas de comunicación más generalizadas. Un ejemplo es la cantidad de mujeres que ocupan espacios dedicados a debatir temas relacionados con la comunicación en los parlamentos. En Brasil, por ejemplo, en 2021, solo 11 mujeres (14\% del Banco de Mujeres) ocuparon la Comisión de Ciencia, Tecnología, Informática y Comunicación de la Cámara de Diputados de Brasil, 6 de las cuales pertenecían a partidos de derecha y centro derecha y 5 de partidos de izquierda y centro izquierda. Por otro lado, 26 mujeres (33\% del Banco de Mujeres) ocuparon la Comisión de Seguridad Social y Familia. Se sabe que las mujeres, al llegar a espacios políticos formales, tienden a enfocar su trabajo en políticas de cuidado, como salud, educación y derechos humanos, pero la comunicación también 
carece de la presencia de mujeres alineadas con la ideología feminista para ser más justas y representativas.

Sin embargo, poco también se vio en los documentos informaciones relacionadas a la problemática interseccional incidiendo sobre la comunicación, o sea acerca del alejamiento de mujeres negras, indígenas, homosexuales o pobres, del ambiente productivo de los medios de comunicación, lo que representa un indicio de la baja fuerza de los debates producidos por esos grupos en los foros internacionales cuando el tema de la comunicación es discutido.

\section{Consideraciones Finales}

El presente artículo demostró que el derecho a la comunicación, si redibujado llevando en cuenta la perspectiva feminista, puede servir como instrumento para la elaboración de políticas públicas que amplíen la visibilidad y la pluralidad de voces de las mujeres en la esfera pública, alcanzando lo que deseaban las participantes de las Conferencias Mundiales de Mujeres. Sin embargo, el análisis de los documentos evidenció que en cada nueva Conferencia, las mujeres entendieron que no podían ser sujetos pasivos ante los procesos de comunicación, sino que debían ingresar a sus estructuras productivas para enfrentar la reproducción de estereotipos de género que impactaban negativamente en sus acciones en la vida cultural, social y política. No obstante, aún falta la reflexión de que, incluso cuando se alcanzan los roles de decisión dentro de los medios de comunicación, las mujeres no siempre llevan una perspectiva feminista dentro de estas organizaciones. En este sentido, sin embargo, se necesitaría mucho tiempo para que la ampliación de la visibilidad de los discursos feministas - que confrontan la hegemonía capitalista y patriarcal - contribuyeran para un efectivo cambio de opinión pública cuanto a los estereotipos de género, ya que ese tipo de opresión adviene de la estructura sistémica, política, cultural y económica de la sociedad.

Pero, ¿cuál es la salida posible? Incluir entre las acciones estratégicas de los próximos documentos internacionales la presencia de las mujeres no solo en los espacios de decisión dentro de los medios de comunicación, sino fortalecer la lucha feminista por mayor representación femenina en los espacios de decisión política, como el legislativo y las áreas técnicas ministeriales relacionadas a la Comunicación. Sin embargo, para que el derecho a la comunicación sea realmente un instrumento de resistencia, de libertad y de autonomía para las mujeres, hay la necesidad de su transformación en formuladoras de las políticas públicas de comunicación en Brasil y América Latina. 


\section{Referencias}

Biroli, F. (2011). Mídia, tipificação e exercícios de poder: a reprodução dos estereótipos no discurso jornalístico. Revista Brasileira de Ciência Política, 6, 71-98.

Carnoy, M. (1986). Estado e Teoria Política. Campinas: Papirus.

Castells, M. (2012). Networks of Outrage and Hope: Social Movements in the Internet Age. Malden: Polity Press.

Coutinho, C. N. (1989). Gramsci: um estudo sobre o pensamento político. Rio de Janeiro: Campus.

Fraser, N. (1993). Repensar el ámbito público: una contribución a la crítica de la democracia realmente existente. Revista Debate feminista, 7, 23-58

Fraser, N. (2000). ¿De la redistribución al reconocimiento? Dilemas de la justicia en la era «postsocialista». New Left Review, o, 1-30.

Gallagher, M. (2011). Gender and Communication Policy: Struggling for Space. En Mansell, R. \& Raboy, M. (Ed.) The Handbook of Global Media and Communication Policy (pp. 451466). Inglaterra: Blackwell Publishing.

Habermas, J. (1981). Historia y crítica de la opinión pública: La transformación estructural de la vida pública. Barcelona: Gustavo Gili.

Jensen, H. (2006). Women's human rights in the information society. En Jørgensen, R. F. Human Rights in the Global Information Society (pp. 235-261) Cambridge: MIT Press.

Miguel, L. F., Biroli, F. (2010). Caleidoscópio convexo: Mulheres, política e mídia. São Paulo: UNESP.

Naciones Unidas (1985). Report of the world conference to review and appraise the achievements of the United Nations Decade for Women. Disponible en: drive.google.com/open?i$\mathrm{d}=$ oB3pWva5IhoocXıFvNEtfNERfaDA.

Naciones Unidas (1996). Informe de la Cuarta Conferencia Mundial sobre la Mujer. Disponible en: https://www.un.org/womenwatch/daw/beijing/pdf/Beijing\%2ofull\%2oreport\%2oS. pdf.

Okin, S. (1979). Women in Western Political Thought. Princeton: Princeton University Press.

Ramos, M. C. (2005). Comunicação, direitos sociais e políticas públicas. In: Melo, J. M. de; Satlher, L. Direitos à Comunicação na Sociedade da Informação (pp. 245-253). São Bernardo do Campo: Umesp.

Rosa, I. C. C. (2014) Raça e Gênero nas formações discursivas sobre a identidade profissional de jornalistas. In: Anais do XVI Congresso de Ciências da Comunicação na Região Centro-Oeste. Brasília: Intercom.

Ross, K. (2017) As mulheres nas estruturas de tomada de decisão nos meios de comunicação europeus. Media \& Jornalismo, 17(30), 63-69.

Secretaria de Comunicação Social da Presidência da República SECOM (2016). Pesquisa Brasileira de Mídia 2016. Disponível em: https://drive.google.com/open?id=oB3pWva5IhoocbmNTaWZOaWVjQm8.

Organización de las Naciones Unidas para la Educación, la Ciencia y la Cultura (1983) Um mundo e muitas vozes - comunicação e informação na nossa época. Rio de Janeiro: Editora da Fundação Getúlio Vargas.

Young, I. M. (1990). Justice and the politics of difference. Princeton: Princeton. 
